\title{
AN EXPERIMENT ON THE EXPANSION OF WATER.
}

By Edward W. Davidson, Huron College, Huron, South Dakota.

The object of this experiment is to let the student discover for himself the expansion curve for water between $60^{\circ}$ and $-10^{\circ}$, C. No claim is made to originality in the work, but the method used is so simple that it may be used conveniently in almost any laboratory, and it has given very gratifying results. The completed work lays graphically before the eye of the student the manner in which water expands and the relation existing between the apparent expansion and the real expansion. It shows clearly just how important a factor is the expansion of the glass; and it enables the student to answer for himself the question which his ordinary text-books usually do not answer, "Does water continue to expand when cooled below the freezing point, or does it contract?”

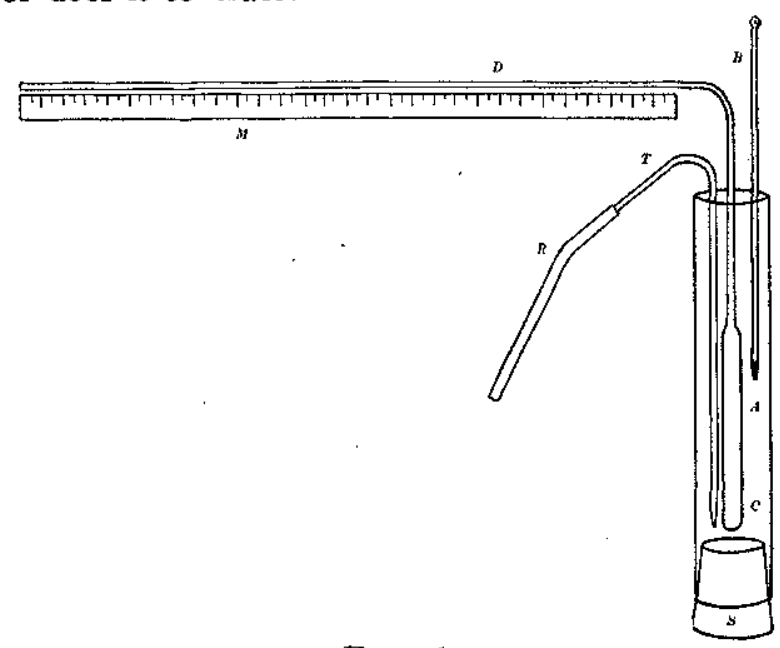

FIG. 1.

The essential parts of the apparatus are shown in figure 1 . $A$ is a bulb about 15 or $20 \mathrm{~cm}$. long and about $1.5 \mathrm{~cm}$. in diameter. It is sealed to a capillary tube, $d$, about a meter long and of about $0.5 \mathrm{~mm}$. bore. The capillary may be bent at right angles above the bulb, thus bringing the atached scale, $m$, into a horizontal position.

The cross-sectional area of the capillary tube is determined by heating the bulb and allowing it to suck mercury into the tube as it cools. If the tube is held in a nearly horizontal posi- 
tion, a column 70 or $80 \mathrm{~cm}$. in length may readily be drawn into it and measured, and it is then weighed in another vessel and the area of the cross-section of the tube is computed from this data.

Next the bulb and tube are weighed dry and then filled with distilled water from which the air has recently been removed by boiling. If warm water is used the bulb may readily be filled by repeatedly heating and allowing to cool--the end of the capillary being held under water while the bulb is cooling. At room temperature the water should stand about $25 \mathrm{~cm}$. from the bend in the capillary.

The tube and bulb are now weighed again to determine the amount of water being studied. It will be noted that there is some water in the capillary tube which does not experience changes in temperature with that in the bulb. The volume of this is small, however, in comparison with the volume of the bulb, and the work may be made accurate to three places without making a correction for this.

The bulb is now inserted in a water bath and brought successively to temperatures of $20^{\circ}, 40^{\circ}$, and $60^{\circ}$. At these temperatures the position of the water in the tube is noted by means of the meter stick, $\mathrm{m}$, which is secured to the tube.

Without changing the position of the meter stick on the tube, the water bath is replaced by an ether bath as shown in the figure. $\mathrm{C}$ is a glass tube having a diameter of about 1.5 inches, and about 1 foot in length. It is closed tightly at the bottom with a cork stopper. The work will be much more successful if the tube, $c$, is itself encased in a jacket to prevent receiving heat from the room by radiation. The boiler of an ordinary calorimeter makes a good outer jacket.

The tube, c, is now filled with ether to a point above the bulb, and air is blown in through the glass tube, $t$, which reaches to the bottom of the ether and is drawn down to capillary dimensions at the lower end. The best air supply is a compression tank from which the blast may be regulated by adjusting the outlet cock. Satisfactory results may be obtained by using an ordinary bellows, but a constant temperature is not so easily maintained. A thermometer, $b$, is inserted in the ether and should be clamped against the side of the vessel in order to prevent difficulties in reading temperatures below the freezing point. The bubbles of air serve as an efficient stirrer, and for that reason the thermometer need not be moved from place to place.

With this arrangement, readings are readily taken every two 
degrees from $10^{\circ}$ to $-10^{\circ}$. If the apparatus is not jarred, the work may be carried this far with little danger of freezing.

After the readings are taken, a graph is plotted using temperatures as abscissas and apparent volumes as ordinates. Four degrees is taken as the temperature at which the volume in cubic centimeters is numerically equal to the weight in grams. The graph for the volume of the glass may be made by drawing a straight line through the points representing its volume at 4 and at 60 . The graph for the real volumes is now plotted by simply adding the expansion of the glass bulb to the apparent expansion.

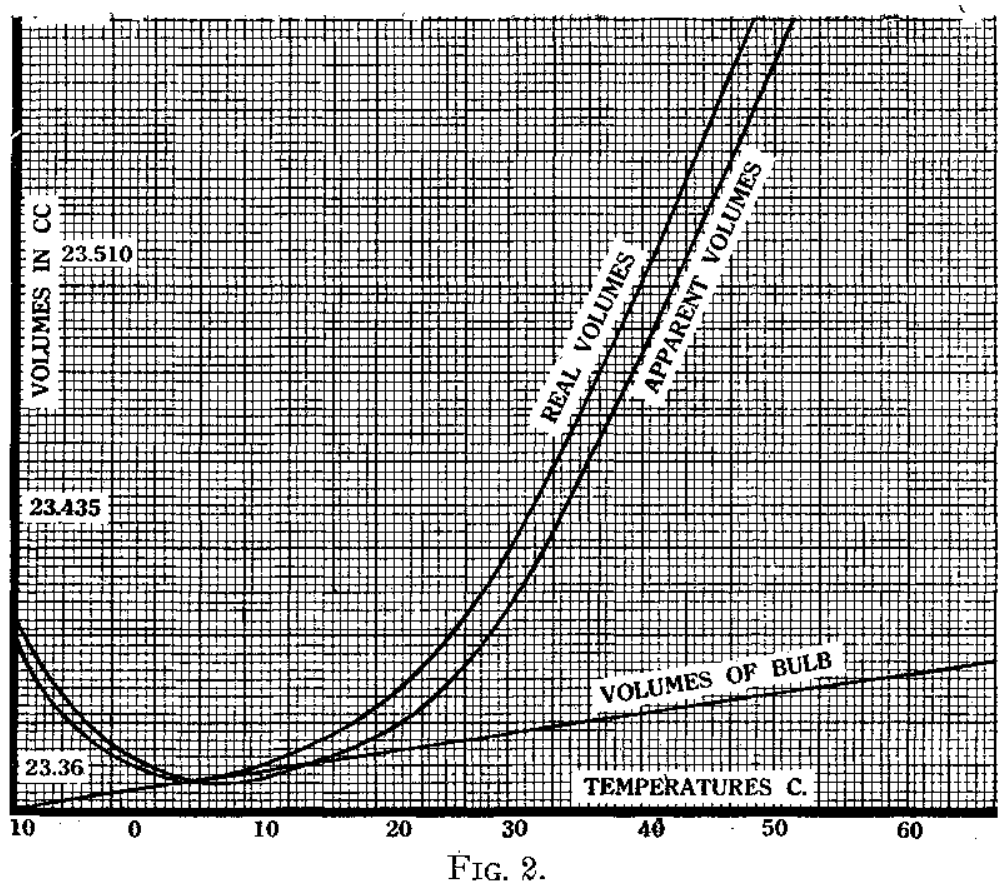

Figure 2 shows a typical example of the results attained by students. It will be noted that at $6^{\circ}$ the apparent volume goes below the minimum value for the real volume, and that from $6^{\circ}$ to $4^{\circ}$ the glass contracts more rapidly than the water, making all three lines meet at $4^{\circ}$. As the temperature goes beolw $4^{\circ}$ the apparent volume is, of course, greater than the real volume, and the student will notice that the real volume increases a little more rapidly as the temperature is lowered below the point of maximum density than it does as the temperature is raised above that point. 